\title{
Effects of Rivastigmine Combined with Reinhartdt and Sea Cucumber Capsule in Patients with Mild-to-Moderate Parkinson's Disease Dementia: A Pilot Study
}

\author{
Yongxing Yan'1, Lizhen Liang1* ${ }^{*}$ Tao Xie², Yonghui Shen"1, Yanjing Cao1 \\ ${ }^{1}$ Department of Neurology, The Third People's Hospital of Hangzhou, Hangzhou, China \\ ${ }^{2}$ Department of Neurology, University of Chicago Medicine, Chicago, USA \\ Email: ${ }^{*}$ yuanyr@sohu.com
}

Received 17 April 2014; revised 20 May 2014; accepted 4 June 2014

Copyright (C) 2014 by authors and Scientific Research Publishing Inc.

This work is licensed under the Creative Commons Attribution International License (CC BY). http://creativecommons.org/licenses/by/4.0/

(c) (i) Open Access

\section{Abstract}

Many patients with Parkinson's disease suffer cognitive impairment or dementia. Cholinesterase inhibitors (ChEIs) have positive effects on patients with Parkinson's Disease Dementia (PDD). But it is only improve symptoms. There is no etiological cure for PDD. So, In order to achieve the best outcomes, the combination of ChEIs and other therapeutic strategies is needed to study. In the present study, we investigate the efficacy and safety of rivastigmine combined with Reinhartdt and Sea Cucumber Capsule (RSC) in patients with mild-to-moderate PDD, and its effect on thyroid function. There were 52 patients were randomly assigned to receive either rivastigmine $(3 \mathrm{mg} /$ day) or rivastigmine plus RSC ( $2.7 \mathrm{~g} /$ day $)$ treatment for 24 weeks. Efficacy was investigated by the change of the scores of Alzheimer's Disease Assessment Scale cognitive subscale (ADAS-Cog), Activities of Daily Life (ADL) and Unified Parkinson's Disease Rating Scale (UPDRS) part III (motor scale). Meanwhile, thyroid hormone levels were detected before and after 12 weeks, 24 weeks treatment in all patients. Results showed that the patients treated with rivastigmine plus RSC showed more improvement in the cognition and the daily life activities compared to those treated with rivastigmine alone. Significant difference was present after being treated for 12 weeks or more. However, no group difference was found on UPDRS part III, thyroid hormone level change and the incidence of adverse events $(11.1 \%$ vs $16.0 \%)$ between the two groups of treatment. Adverse effects were nausea and vomiting which were the main reasons for the dropout. The finding suggests that Rivastigmine plus RSC may improves the treatment effects in cognition and the ADL of the patients with mild-to-moderate PDD, compared with the rivastigmine treatment alone. However, no effect was observed on the motor symptoms and thyroid hormone levels. In addition, this joint treatment is safe.

\footnotetext{
${ }^{*}$ Corresponding author.
}

How to cite this paper: Yan, Y.X., Liang, L.Z., Xie, T., Shen, Y.H. and Cao, Y.J. (2014) Effects of Rivastigmine Combined with Reinhartdt and Sea Cucumber Capsule in Patients with Mild-to-Moderate Parkinson's Disease Dementia: A Pilot Study. Chinese Medicine, 5, 94-103. http://dx.doi.org/10.4236/cm.2014.52011 


\section{Keywords}

\section{Parkinson's Disease, Cognitive Function, Rivastigmine, Reinhartdt and Sea Cucumber}

\section{Introduction}

Parkinson's disease characterized by bradykinesia, tremor, rigidity, and postural instability is one of common neurodegenerative disease, its incidence of 14 per 100,000 [1] [2]. In China, the incidence rate is about $2 \%$ in the population of age $\geq 65$-year old [3]. In addition to the typical motor symptoms of Parkinson's disease, it also have cognitive impairment or dementia [4]. Some studies have shown that about $30 \%$ of patients suffer dementia in Parkinson's disease [5] [6]. Parkinson's Disease Dementia (PDD) greatly affects functioning and quality of life. It can also increase caregiver burden, health-related costs, and duration of hospital stays etc [7]-[9].

In patients with PDD, cognitive changes are linked to disease-related disturbances of cholinergic activity [10]. Bohnen NI et al. found cholinergic deficits in PDD are more obvious in Alzheimer's disease, compared with similar levels of cognitive impairment [11]. Studies of cholinergic deficits in patients with PDD suggested that treatment of cholinesterase inhibitors (ChEIs) may effectively improve the impact of the disease on the cholinergic circuits. A Cochrane analysis supports the use of ChEIs in patients with PDD and shows that ChEIs have positive effects on cognitive function [12].

Although ChEIs have effects on PDD, up to date, many treatments all were symptomatic therapy. there is no etiological cure for PDD. In order to achieve the best treatment outcomes, the combination of ChEIs and other therapeutic strategies is widely studied. In China, some traditional herbs have been reported to improve cognitive function in dementia patients [13]-[15]. The combination of traditional herb and ChEIs suggested an obvious effect in treating the patients with Alzheimer's disease and vascular dementia [16] [17].

Reinhartdt and Sea Cucumber Capsule (RSC) has been used for many years in China to improve the cognition of Alzheimer's disease and vascular dementia [18] [19]. Here we hypothesize that RSC combined with a ChEIs rivastigmine may improve the treatment of mild-to-moderate PDD. the efficacy and tolerance of rivastigmine combined with RSC will be examined on the Alzheimer's Disease Assessment Scale cognitive subscale (ADAS-Cog), Activities of Daily Life (ADL) and Unified Parkinson's Disease Rating Scale (UPDRS) part III (motor scale) of the patients with mild-to-moderate PDD, and its effect on thyroid function axis.

\section{Materials and Methods}

\subsection{Participants}

Patients received a diagnosis of Parkinson's disease according to the clinical diagnostic criteria of the United Kingdom Parkinson's Disease Society Brain Bank [20] and a diagnosis of dementia due to Parkinson's disease based on criteria established by a Movement Disorders Society taskforce [21]. Patients had mild-to-moderately dementia as defined by a Mini-Mental State Examination (MMSE) score of 10 to 26. The vision, hearing and mental states of all patients were allowed cooperation to complete neuropsychological testing. All cases were in good nutritional status and had normal range of liver and kidney function in the blood. There was no history of thyroid disease, or drugs which can affect thyroid metabolism nearly a month.

Exclusion criteria included any causes of dementia other than Parkinson's disease; a history of a major depressive disorder; a history of hypersensitivity to ChEIs; the use of a cholinesterase inhibitor or other traditional herbal medicine which can interfere with the evaluation during the four weeks before randomization; serious abnormal heart, liver, kidney function; history of allergies and seafood allergy; a known or suspected history of alcoholism or drug abuse.

\subsection{Study Design}

In this 24-week, randomized, open-label and evaluator-blinded controlled study, all patients were informed and agreed to be consecutively enrolled in the study by their physicians. The random number table was used for randomized controlled trial design in the study. Basically, we randomly picked one number in the random num- 
ber table for the first patient who was enrolled in the study. And the numbers following the first picked number in the random number table were consecutively assigned to other subjects according to the order of treatment. The subjects with singular number were treated with rivastigmine (Brand name: Exelon, Novartis Pharmaceutical Co., Switzerland) and the subjects with plural number were treated with rivastigmine plus Reinhartdt and Sea Cucumber Capsule (Brand name: Fufanghaishe, Hangkang Ocean Biological Pharmaceutical Co. Ltd., China).

During the treatment, all participants in rivasigmine group took rivastigmine orally at the doses of $3 \mathrm{mg} / \mathrm{day}$, divided twice a day. In the combination treatment group, RSC was given at the dose of $0.9 \mathrm{~g} /$ time, three times a day orally. No other ChEIs or nootropics was taken by the patients in both groups during the treatment.

Patients were required to attend a regular interview every 4 weeks for the following evaluations. The following evaluations were routine physical and mental examination, psychometric tests (ADAS-Cog, ADL and UPDRS-III), and adverse events monitoring. Blood, urine, stool routine, liver and kidney function and Electrocardiography (ECG) were detected before and after 12 weeks and 24 weeks treatment in all patients. Thyroid hormone levels were also checked by immune chemiluminescence detection at the same time. Test box was provided by Bayer Co. Each normal reference values were: $\mathrm{TT}_{3}: 0.8$ - $2.2 \mu \mathrm{g} / \mathrm{L} ; \mathrm{TT}_{4}: 42$ - $135 \mu \mathrm{g} / \mathrm{L} ; \mathrm{FT}_{3}: 2.5$ $9.82 \mathrm{pmol} / \mathrm{L} ; \mathrm{FT}_{4}$ : 10 - 25 pmol/L; TSH: 0.2 - $7.0 \mathrm{mIU} / \mathrm{L}$ ).

This study was conducted in accordance with the ethical standards of the responsible committee on human experimentation and with the Helsinki Declaration as revised in 1983.

\subsection{Assessing Measurements}

ADAS-Cog was used to measure the cognitive domains of PDD. The cognitive portion of the ADAS assesses orientation, memory, language, visuospatial, and praxis functions. Total scores ranged from 0 to 70 , the higher the score, the greater the cognitive impairment. ADL was assessed with a standardized 20-item ADL scale. The scores ranged from 0 to 80 and a higher score, the greater less functional ability.

Changes in symptoms of Parkinson's disease were assessed by means of the motor section of the UPDRS (part III), for which scores can range from 0 to 108 points, with higher scores indicating more severe motor symptoms.

During the whole study, blinded and well trained evaluators performed the experiments to test MMSE, ADAS-Cog, ADL, UPDRS-III. All evaluators analyzed the data without any information about the patient group.

\subsection{Statistical Analysis}

Analyses were done on data from all patients who underwent randomization and who received at least one dose of study drug, applying the principle of intention-to-treat (ITT). We used the last-observation-carried-forward (LOCF) method to impute values if no follow-up information was available.

Statistical analyses were performed with the use of SPSS software, version 10.0. The basal comparison of characteristics in patients with two treatments was analyzed by a chi square test and student's t test. Changes from baseline in the ADAS-cog, ADL and UPRDS-III scores were assessed by means of analysis of covariance. Thyroid hormone levels data were expressed as mean \pm standard deviation. Variance analysis (one-way ANOVA) was used in group while the Q test (post-hoc multiple comparisons between groups were made with Least-significant difference) was used between groups. A p-value $<0.05$ was considered statistically significant.

\section{Results}

\subsection{Patient Disposition}

A total of 58 eligible patients were enrolled to attend the study. During the study, 3 patients previously took cholinesterase inhibitors, 2 patients quitted the study and 1 patient had severe renal dysfunction. Those 6 patients were excluded from our randomized study for treatment. The Consolidated Standards of Reporting Trias (CONSORT)-like flowchart was showed in Figure 1. The rest of 52 subjects were randomly divided into two treatment group. One group of 25 patients (11 males and 14 females) of aged $69.7 \pm 4.2$ years old (from 60 to 76 


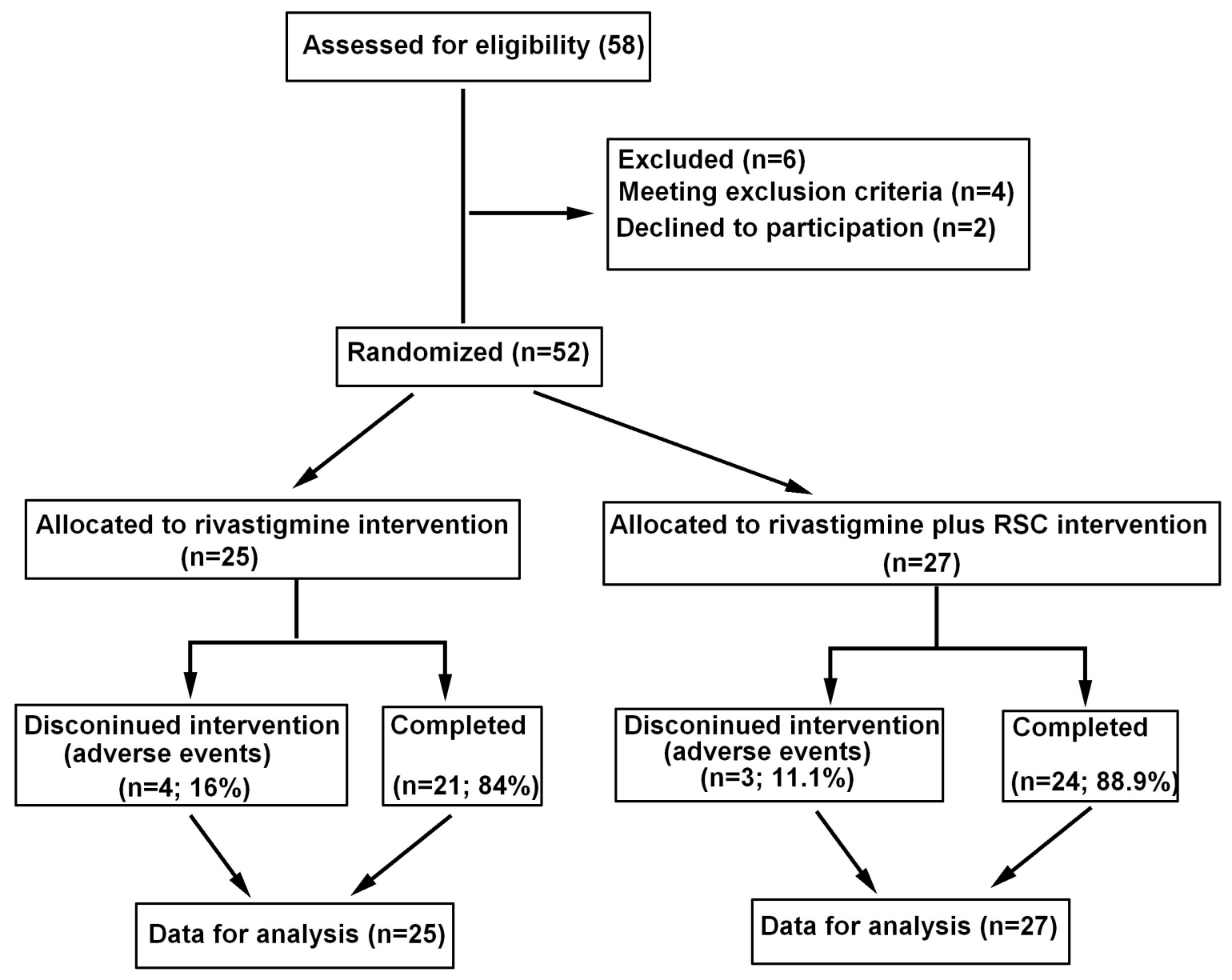

Figure 1. The CONSORT-like flowchart of patients.

years old) were treated with rivastigmine alone. The average duration of PDD for those patients was $1.6 \pm 0.9$ years. Another group of 27 patients (16 males and 11 females) of aged $70.6 \pm 6.9$ years (from 58 to 82 years old) were treated with rivastigmine plus RSC. The average duration of PDD was $1.6 \pm 0.8$ years. The results did not show any significant difference between the two groups in baseline data, the characteristics of two groups were shown in Table 1.

All patients with PDD from the two groups were also administered the following concomitant medications (single rivastigmine treatment vs rivastigmine plus RSC): levodopa agents (96.0\% vs $92.6 \%$ ), dopamine agonists agents (76.0\% vs $81.5 \%$ ), Amantadine (36.0\% vs $25.9 \%$ ), Comtan (catechol-O-methyltransferase inhibitor; Entacapone) (16.0\% vs $11.1 \%$ ), antidepressants (28.0\% vs $22.2 \%)$, antianxiety agents (32.0\% vs $37.0 \%$ ), and antipsychotic agents $(32.0 \%$ vs $33.3 \%)$. There were no significant differences between two groups $(\mathrm{p}>0.05)$ in most common concomitant medications.

\subsection{Efficacy}

The ADAS-Cog scores declined at the beginning of the treatment in both groups. This meant the cognition of the patients improved after the treatments. Compared to the rivastigmine treatment alone group, rivastigmine plus RSC group had significantly more reduction in ADAS-Cog scores and ADL scores. The ADAS-Cog scores in the combined group had an obvious decrease ( $p<0.05$ at 12 weeks, $\mathrm{p}<0.01$ after 16 weeks) and the patients displayed much better cognition since the 12th week (Figure 2). The ADL scores also significantly decreased in rivastigmine plus RSC treatment group from the 12th week to the end of the study as compared with rivastigmine treatment alone (Figure 3). There is no difference was observed in the UPDRS part III score between two groups at each time (Figure 4). 


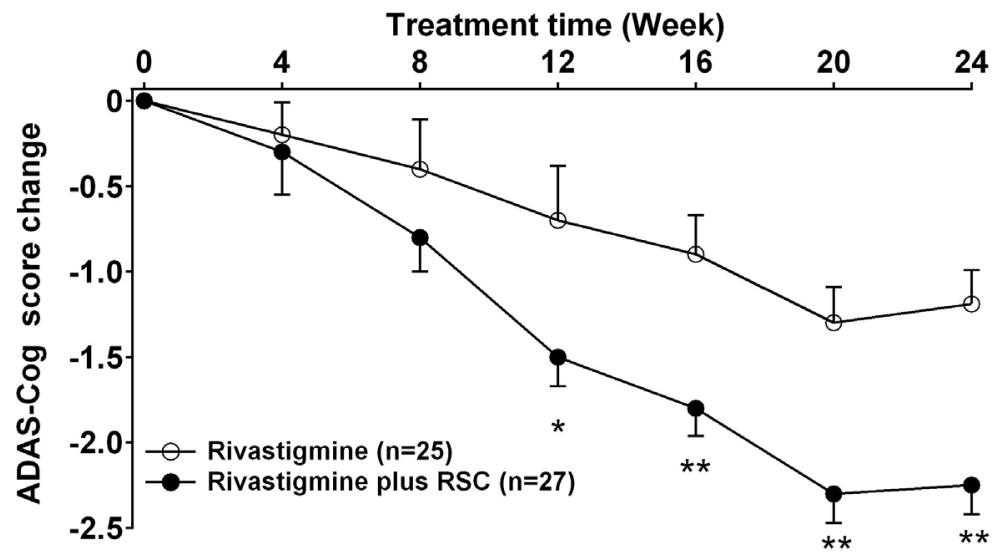

Figure 2. The change of the scores of ADAS-Cog in each group (mean $\pm \mathrm{SD}$ ). ${ }^{*}: \mathrm{p}<0.05,{ }^{* *}: \mathrm{p}<0.01$ between the rivastigmine treatment and the rivastigmine plus RSC treatment.

Table 1. The characteristics of the patients in each group.

\begin{tabular}{cccc}
\hline Parameter & Rivastigmine, $\mathrm{N}=25$ & Rivastigmine plus RSC, $\mathrm{N}=27$ & Statistic values \\
\hline Sex (male/female)-no. & $11 / 14$ & $16 / 11$ & $\mathrm{x}^{2}=1.211 ; \mathrm{p}=0.271$ \\
Age (mean \pm SD) & $69.7 \pm 4.2$ & $70.6 \pm 6.9$ & $\mathrm{t}=0.571 ; \mathrm{p}=0.570$ \\
Education (mean \pm SD) & $9.1 \pm 2.1$ & $8.9 \pm 3.1$ & $\mathrm{t}=0.316 ; \mathrm{p}=0.753$ \\
Duration of PD (mean \pm SD) & $7.9 \pm 1.9$ & $7.8 \pm 2.4$ & $\mathrm{t}=0.292 ; \mathrm{p}=0.771$ \\
Duration of PDD (mean \pm SD) & $1.6 \pm 0.9$ & $1.6 \pm 0.8$ & $\mathrm{t}=0.044 ; \mathrm{p}=0.965$ \\
MMSE score (mean \pm SD) & $20.8 \pm 3.9$ & $19.8 \pm 3.8$ & $\mathrm{t}=0.283 ; \mathrm{p}=0.778$ \\
ADAS-cog score (mean \pm SD) & $25.4 \pm 9.4$ & $26.2 \pm 9.1$ & $\mathrm{t}=0.320 ; \mathrm{p}=0.750$ \\
ADL score (mean \pm SD) & $42.6 \pm 9.3$ & $42.1 \pm 11.0$ & $\mathrm{t}=0.173 ; \mathrm{p}=0.863$ \\
UPDRS part III score (mean \pm SD) & $33.6 \pm 11.1$ & $33.3 \pm 12.5$ & $\mathrm{t}=0.092 ; \mathrm{p}=0.927$ \\
Medications used-no. (\%) & & & \\
Levodopa & $24(96 \%)$ & $25(92.6 \%)$ & $\mathrm{x}^{2}=0.277 ; \mathrm{p}=0.599$ \\
Dopamine agonists & $19(76.0 \%)$ & $22(81.5 \%)$ & $\mathrm{x}^{2}=0.234 ; \mathrm{p}=0.629$ \\
Amantadine & $9(36.0 \%)$ & $7(25.9 \%)$ & $\mathrm{x}^{2}=0.618 ; \mathrm{p}=0.432$ \\
Comtan & $4(16.0 \%)$ & $3(11.1 \%)$ & $\mathrm{x}^{2}=0.266 ; \mathrm{p}=0.606$ \\
Antidepressants & $7(28.0 \%)$ & $6(22.2 \%)$ & $\mathrm{x}^{2}=0.231 ; \mathrm{p}=0.631$ \\
Antianxiety agents & $8(32.0 \%)$ & $10(37.0 \%)$ & $\mathrm{x}^{2}=0.146 ; \mathrm{p}=0.703$ \\
Antipsychotic agents & $8(32.0 \%)$ & $9(33.3 \%)$ & $\mathrm{x}^{2}=0.010 ; \mathrm{p}=0.918$ \\
\hline
\end{tabular}

Thyroid hormone levels of the two groups of patients were evaluated before and after 12 weeks, 24 weeks treatment, but no statistical difference was found between the each time period ( $p>0.05$, Table 2).

\subsection{Safety}

The main treatment-related adverse events were nausea and vomiting in this study. Three participants ( 2 patients vomiting, 1 patient nausea) in the rivastigmine plus RSC and four subjects (1 patient vomiting, 3 patients nausea) in the single rivastigmine group experienced mild-to-moderate adverse events related to nausea and vomiting. They all failed to complete the study due to the adverse events. No serious adverse events were occurred during the study. The statistical results found no significant difference in the laboratory and auxiliary examination (blood, urine, stool routine, liver and kidney function, ECG). The discontinuation rate was similar in two groups 


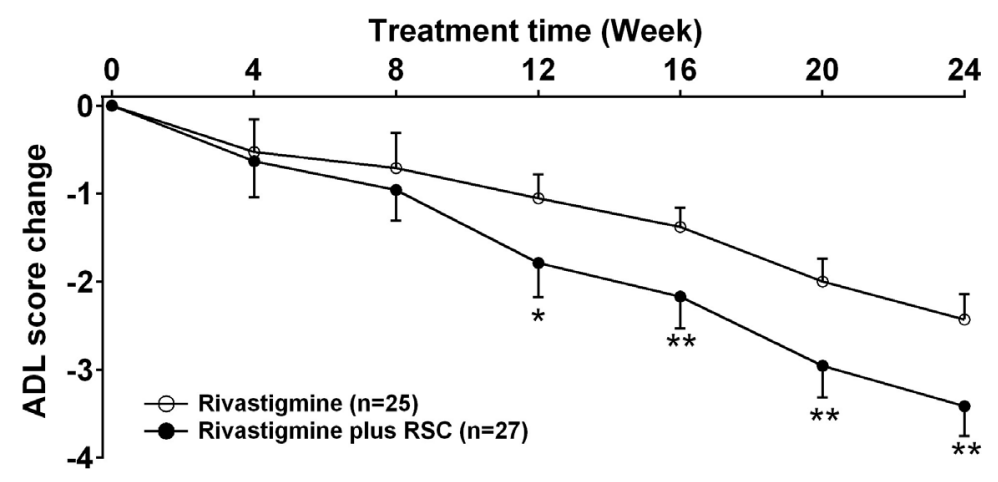

Figure 3. The change of the scores of ADL in each group (mean \pm SD). ${ }^{*} \mathrm{p}<$ $0.05,{ }^{* *} \mathrm{p}<0.01$ between the rivastigmine treatment and the rivastigmine plus RSC treatment.

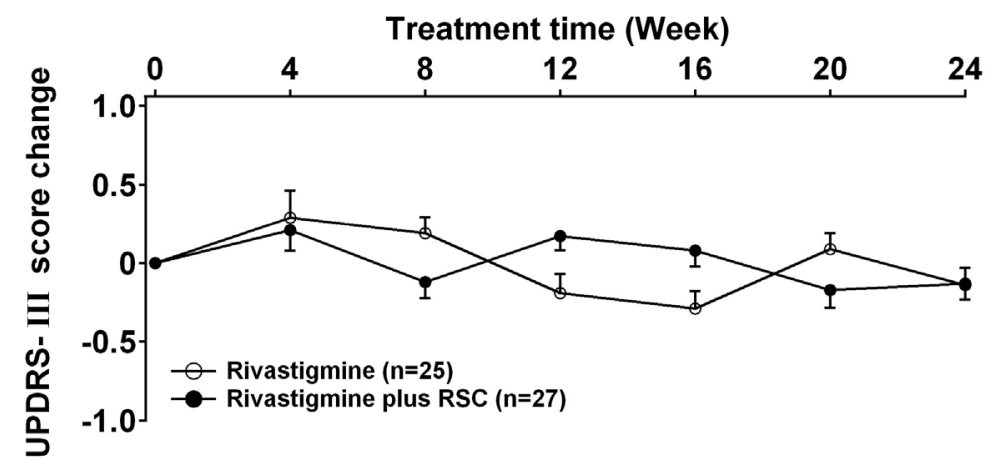

Figure 4. The change of the scores of UPDRS-III in each group (mean \pm SD). There is no difference between two groups at each time.

Table 2. Thyroid hormone levels before and after treatment in each group (mean \pm SD).

\begin{tabular}{cccccccc}
\hline Groups & No. & Period & $\mathrm{TSH}(\mathrm{mIU} / \mathrm{L})$ & $\mathrm{TT}_{3}(\mu \mathrm{g} / \mathrm{L})$ & $\mathrm{TT}_{4}(\mu \mathrm{g} / \mathrm{L})$ & $\mathrm{FT}_{3}(\mathrm{pmol} / \mathrm{L})$ & $\mathrm{FT}_{4}(\mathrm{pmol} / \mathrm{L})$ \\
\hline Rivastigmine & 25 & Before treatment & $4.0 \pm 0.9$ & $1.6 \pm 0.3$ & $76.1 \pm 10.7$ & $5.8 \pm 2.1$ & $18.0 \pm 3.5$ \\
& 25 & After 12 weeks & $4.0 \pm 0.9$ & $1.7 \pm 0.2$ & $74.6 \pm 9.3$ & $5.7 \pm 1.7$ & $17.7 \pm 2.9$ \\
& 25 & After 24 weeks & $4.2 \pm 0.8$ & $1.7 \pm 0.3$ & $76.6 \pm 8.1$ & $5.6 \pm 1.8$ & $17.9 \pm 2.9$ \\
Rivastigmine plus RSC & 27 & Before treatment & $4.1 \pm 0.9$ & $1.7 \pm 0.3$ & $78.2 \pm 10.7$ & $6.0 \pm 1.3$ & $17.8 \pm 3.7$ \\
& 27 & After 12 weeks & $4.1 \pm 1.0$ & $1.7 \pm 0.3$ & $79.2 \pm 9.6$ & $5.7 \pm 1.3$ & $18.1 \pm 3.2$ \\
& 27 & After 24 weeks & $4.2 \pm 0.9$ & $1.6 \pm 0.2$ & $78.0 \pm 9.7$ & $6.1 \pm 1.3$ & $16.9 \pm 3.3$ \\
\hline
\end{tabular}

(11.1\% in rivastigmine plus RSC group; $16.0 \%$ in rivastigmine alone group). No difference was observed between two groups in reasons for discontinuation $(\mathrm{p}>0.05)$.

\section{Discussion}

Dementia in Parkinson's disease is linked to disease-related disturbances of cholinergic activity [10]. Cholinergic neuron loss as the main feature of non-dopaminergic neurons dysfunction was an important pathophysiological mechanism in Parkinson's disease dementia [10] [11]. The main neuropathological change was that the Lewy bodies widely appear in the basal ganglia and the limbic system [22]-[24]. Thus, base on the pathophysiological mechanism, many scholar think that mechanism-based treatments can improve cognition in Parkinson's disease. The first study about ChEIs treatment PDD in 1996, it showed the cognition of patients with PDD improved after treated with tacrine [25]. Although only seven patients with PDD in the study, the result of this study provided the rationale for large randomized controlled trials of ChEIs in PDD. EXPRESS study which a 
24-week randomized placebo-controlled trial, showed that rivastigmine significantly improved cognition and clinical outcomes compared with placebo [26]. Meanwhile ,The results of extension phase also showed that rivastigmine might provide sustained benefits for up to 48 weeks [27].when the patients with PDD were treated with rivastigmine, amplified brain perfusion on Single-photon Emission Computed Tomography and increased $\alpha$-activity on quantitative EEG in frontal regions were found [28] [29]. Now, rivastigmine is widely approved for clinical use in the treatment of PDD [30]. In this study, we observed obvious improvement in cognition and the daily activities of patients with mild-to-moderate PDD after taking rivastigmine $3 \mathrm{mg} / \mathrm{d}$ for 24 weeks. In China, some traditional herbal medicine can improve cognitive function in dementia patients [13]-[15]. RSC is one of traditional Chinese medicine which improves the cognition of Alzheimer's disease and vascular dementia and has been used for many years in China [18] [19]. RSC is a natural product which is made of Hainan semirings sea snakes, Yuzu sea cucumber and polygala tenuifolia by biological engineering technology. The main ingredients were sea snakes, sea cucumbers, Polygala and stone calamus. Researches about RSC in cell and molecular level indicated that it could significantly increase the content of acetylcholine and superoxide dismutase in the brain, and reduce the glutamic acid and lipid peroxide levels. The mechanism for improving cognitive and memory function is changing a variety of brain neurotransmitters and biochemical factors [31]-[33]. ChEIs was also reported to treat the patients with Alzheimer's disease and vascular dementia with a certain effect [17] [34]. In the present study, we observed more improvement in cognition and the daily activities of patients after 24-weeks treatment with rivastigmine plus RSC group compared with rivastigmine alone treatment group. Significant difference was found in ADAC-cog, ADL scores at the 12-weeks. Patients showed better cognitive and behavior abilities with rivastigmine plus RSC treatment. These results suggest that rivastigmine plus RSC treatment has a better effect on improving the cognitive deficit in PDD patients than rivastigmine alone treatment. It also indicated the potency of RSC in delaying the cognitive decline in PDD when treated with rivastigmine simultaneously. In our study, the improvement of the cognition and the daily function of the patients in the combined treated group may be due to the improvement of acetylcholine content in the brain. The improvement of daily living function may be due to the improvement in cognition, as the motor function remains unchanged after the treatment.

Thyroid hormone plays an important role in the central nervous system development and normal function [35] [36]. Slight change in thyroid hormone level even in the normal range may be associated with the elderly emotional and cognitive function change. Previous studies have shown that thyroid hormone levels were closely linked with Alzheimer's disease. Thyroid hormone levels were reported to be changed in Alzheimer's disease patients after cholinesterase inhibitor therapy [37] [38]. Our previous study also found that the RSC combined with donepezil therapy in patients with Alzheimer's disease and vascular dementia raised its $T_{3}, T_{4}$ level, synergistically improving cognitive function [17] [34]. However, in present study, no change about thyroid hormone levels was found before and after 12 weeks and 24 weeks in either single rivastigmine treatment or rivastigmine plus RSC treatment. It is consistent with previous researches that thyroid hormone levels were not correlated to the severity of Parkinson's disease [39] [40].

The predominant adverse events caused by cholinergic disorder are nausea,vomiting, tremor, diarrhea, anorexia, etc. Most of these adverse events were reversible, and were mild to moderate. Although tremor may occurred during the initial treatment period, the analysis about rivastigmine effect on motor effects showed that Parkinson's disease did not get worse during 48 weeks in the EXPRESS study [41]. Adverse events were not observed to be different in UPDRS motor scores including tremor-related items between the control groups and treatment group [24]. Compared to the treatment in previous studies, the combination treatment in our study indicated a lower incidence of side effects (13.5\%, 7 cases). The side effect is the reason for withdrawing from the study. It mainly showed nausea (3 cases), vomiting (4 cases), and symptoms improved after withdraw. No tremor and other movement disorders aggravation were observed. There was no difference in UPDRS motor scores. It may be related to rivastigmine used in small dosage ( $3 \mathrm{mg} /$ day) in our study.

Of cause, some limitations are still present in our study. First, these results may partly reflect a normal clinical treatment, not a double-blind, randomized, controlled trial. Second, the sample size is still small, due to the strict inclusion and exclusion criteria. A better rigorous research with more patients needs to be performed in the future.

\section{Conclusion}

In conclusion, our results show that rivastigmine plus RSC treatment has a better effect in improving the symp- 
toms of the patients with mild-to-moderate PDD than rivastigmine treatment alone. The formula was safe and it had no effect on thyroid hormone levels in PDD patients.

\section{Competing Interests}

The authors have declared that no competing interest exists.

\section{References}

[1] Jankovic, J. (2008) Parkinson's Disease: Clinical Features and Diagnosis. Journal of Neurology, Neurosurgery \& Psychiatry, 79, 368-376. http://dx.doi.org/10.1136/jnnp.2007.131045

[2] Hirtz, D., Thurman, D.J., Gwinn-Hardy, K., Mohamed, M., Chaudhuri, A.R. and Zalutsky, R. (2007) How Common Are the "Common” Neurologic Disorders? Neurology, 68, 326-337. http://dx.doi.org/10.1212/01.wnl.0000252807.38124.a3

[3] Zhang, Z.X., Roman, G.C., Hong, Z., Wu, C.B., Qu, Q.M., Huang, J.B., Zhou, B., Geng, Z.P., Wu, J.X., Wen, H.B., Zhao, H. and Zahner, G.E. (2005) Parkinson's Disease in China: Prevalence in Beijing, Xian, and Shanghai. Lancet, 365, 595-597. http://dx.doi.org/10.1016/S0140-6736(05)17909-4

[4] Galvin, J.E., Pollack, J. and Morris, J.C. (2006) Clinical Phenotype of Parkinson Disease Dementia. Neurology, 67, 1605-1611. http://dx.doi.org/10.1212/01.wnl.0000242630.52203.8f

[5] Aarsland, D., Zaccai, J. and Brayne, C. (2005) A Systematic Review of Prevalence Studies of Dementia in Parkinson's Disease. Movement Disorders, 20, 1255-1263. http://dx.doi.org/10.1002/mds.20527

[6] Riedel, O., Klotsche, J., Spottke, A., Deuschl, G., Förstl, H., Henn, F., Heuser, I., Oertel, W., Reichmann, H., Riederer, P., Trenkwalder, C., Dodel, R. and Wittchen, H.U. (2010) Frequency of Dementia, Depression, and Other Neuropsychiatric Symptoms in 1449 Outpatients with Parkinson's Disease. Journal of Neurology, 257, 1073-1082. http://dx.doi.org/10.1007/s00415-010-5465-z

[7] Winter, Y., von Campenhausen, S., Arend, M., Longo, K., Boetzel, K., Eggert, K., Oertel, W.H., Dodel, R. and Barone, P. (2011) Health-Related Quality of Life and Its Determinants in Parkinson's Disease: Results of an Italian Cohort study. Parkinsonism \& Related Disorders, 17, 265-269. http://dx.doi.org/10.1016/j.parkreldis.2011.01.003

[8] Vossius, C., Larsen, J.P., Janvin, C. and Aarsland, D. (2011) The Economic Impact of Cognitive Impairment in Parkinson's Disease. Movement Disorders, 26, 1541-1544. http://dx.doi.org/10.1002/mds.23661

[9] Fletcher, P., Leake, A. and Marion, M.H. (2011) Patients with Parkinson’s Disease Dementia Stay in the Hospital Twice as Long as Those without Dementia. Movement Disorders, 26, 919. http://dx.doi.org/10.1002/mds.23573

[10] Klein, J.C., Eggers, C., Kalbe, E., Weisenbach, S., Hohmann, C., Vollmar, S., Baudrexel, S., Diederich, N.J., Heiss, W.D. and Hilker, R. (2010) Neurotransmitter Changes in Dementia with Lewy Bodies and Parkinson Disease Dementia in Vivo. Neurology, 74, 885-892. http://dx.doi.org/10.1212/WNL.0b013e3181d55f61

[11] Bohnen, N.I., Kaufer, D.I., Ivanco, L.S., Lopresti, B., Koeppe, R.A., Davis, J.G., Mathis, C.A., Moore, R.Y. and DeKosky, S.T. (2003) Cortical Cholinergic Function Is More Severely Affected in Parkinsonian Dementia Than in Alzheimer Disease: An in Vivo Positron Emission Tomographic Study. Arch Neurol, 60, 1745-1748. http://dx.doi.org/10.1001/archneur.60.12.1745

[12] Rolinski, M., Fox, C., Maidment, I. and McShane, R. (2012) Cholinesterase Inhibitors for Dementia with Lewy Bodies, Parkinson's Disease Dementia and Cognitive Impairment in Parkinson's Disease. Cochrane Database of Systematic Reviews, 3, CD006504. http://dx.doi.org/10.1002/14651858.CD006504.pub2

[13] Wu, T.Y., Chen, C.P. and Jinn, T.R. (2011) Traditional Chinese Medicines and Alzheimer's Disease. Taiwanese Journal of Obstetrics and Gynecology, 50, 131-135. http://dx.doi.org/10.1016/j.tjog.2011.04.004

[14] Lin, H.Q., Ho, M.T., Lau, L.S., Wong, K.K., Shaw, P.C. and Wan, D.C. (2008) Anti-Acetylcholinesterase Activities of Traditional Chinese Medicine for Treating Alzheimer’s Disease. Chemico-Biological Interactions, 175, 352-354. http://dx.doi.org/10.1016/j.cbi.2008.05.030

[15] Kim, H.G. and Oh, M.S. (2012) Herbal Medicines for the Prevention and Treatment of Alzheimer's Disease. Current Pharmaceutical Design, 18, 57-75. http://dx.doi.org/10.2174/138161212798919002

[16] Li, D.Q., Zhou, Y.P. and Yang, H. (2012) Donepezil Combined with Natural Hirudin Improves the Clinical Symptoms of Patients with Mild-to-Moderate Alzheimer's Disease: A 20-Week Open-Label Pilot Study. International Journal of Medical Sciences, 9, 248-255. http://dx.doi.org/10.7150/ijms.4363

[17] Yan, Y.X., Liang, L.Z. and Zhou, Z.L. (2007) Clinical Study of Combined Treatment with Compound Reinhartdt and Sea Cumber Capsule and Donepezil for Vascular Dementia. Chinese Journal of Integrated Traditional and Western Medicine, 27, 887-890. 
[18] Wang, C.F., Ma, Y.X., Gu, Y.D., Xie, S.Z., Yu, Z.Y. and Yang, J.Y. (2000) A Double-Blind Clinical Study on the Reinhardt and Sea Cucumber Capsule in Treating Dementia in the Aged. Geriatrics \& Health Care, 6, 11-15.

[19] Kang, J. (2009) Research of Compound Reinhartdt and Sea Cumber Capsule Treating Encephalopathy. World Chinese Medicine, 4, 58-59.

[20] Gibb, W.R. and Lees, A.J. (1988) The Relevance of the Lewy Body to the Pathogenesis of Idiopathic Parkinson's Disease. Journal of Neurology, Neurosurgery \& Psychiatry, 51, 745-752. http://dx.doi.org/10.1136/jnnp.51.6.745

[21] Emre, M., Aarsland, D., Brown, R., Burn, D.J., Duyckaerts, C., Mizuno, Y., Broe, G.A., Cummings, J., Dickson, D.W., Gauthier, S., Goldman, J., Goetz, C., Korczyn, A., Lees, A., Levy, R., Litvan, I., McKeith, I., Olanow, W., Poewe, W., Quinn, N., Sampaio, C., Tolosa, E. and Dubois, B. (2007) Clinical Diagnostic Criteria for Dementia Associated with Parkinson's Disease. Movement Disorders, 22, 1689-1707. http://dx.doi.org/10.1002/mds.21507

[22] Hurtig, H.I., Trojanowski, J.Q., Galvin, J., Ewbank, D., Schmidt, M.L., Lee, V.M., Clark, C.M., Glosser, G., Stern, M.B., Gollomp, S.M. and Arnold, S.E. (2000) Alpha-Synuclein Cortical Lewy Bodies Correlate with Dementia in Parkinson's Disease. Neurology, 54, 1916-1921. http://dx.doi.org/10.1212/WNL.54.10.1916

[23] Aarsland, D., Perry, R., Brown, A., Larsen, J.P. and Ballard, C. (2005) Neuropathology of Dementia in Parkinson's Disease: A Prospective, Community-Based Study. Annals of Neurology, 58, 773-776.

http://dx.doi.org/10.1002/ana.20635

[24] Braak, H., Rüb, U., Jansen Steur, E.N., Del Tredici, K. and de Vos, R.A. (2005) Cognitive Status Correlates with Neuropathologic Stage in Parkinson Disease. Neurology, 64, 1404-1410. http://dx.doi.org/10.1212/01.WNL.0000158422.41380.82

[25] Hutchinson, M. and Fazzini, E. (1996) Cholinesterase Inhibition in Parkinson's Disease. Journal of Neurology, Neurosurgery \& Psychiatry, 61, 324-325. http://dx.doi.org/10.1136/jnnp.61.3.324-a

[26] Emre, M., Aarsland, D., Albanese, A., Byrne, E.J., Deuschl, G., De Deyn, P.P., Durif, F., Kulisevsky, J., van Laar, T., Lees, A., Poewe, W., Robillard, A., Rosa, M.M., Wolters, E., Quarg, P., Tekin, S. and Lane, R. (2004) Rivastigmine for Dementia Associated with Parkinson's Disease. The New England Journal of Medicine, 351, 2509-2518. http://dx.doi.org/10.1056/NEJMoa041470

[27] Poewe, W., Wolters, E., Emre, M., Onofrj, M., Hsu, C., Tekin, S. and Lane, R., EXPRESS Investigators (2006) Long-Term Benefits of Rivastigmine in Dementia Associated with Parkinson's Disease: An Active Treatment Extension Study. Movement Disorders, 21, 456-461. http://dx.doi.org/10.1002/mds.20700

[28] Ceravolo, R., Volterrani, D., Frosini, D., Bernardini, S., Rossi, C., Logi, C., Manca, G., Kiferle, L., Mariani, G., Murri, L. and Bonuccelli, U. (2006) Brain Perfusion Effects of Cholinesterase Inhibitors in Parkinson's Disease with Dementia. Journal of Neural Transmission, 113, 1787-1790. http://dx.doi.org/10.1007/s00702-006-0478-6

[29] Fogelson, N., Kogan, E., Korczyn, A.D., Giladi, N., Shabtai, H. and Neufeld, M.Y. (2003) Effects of Rivastigmine on the Quantitative EEG in Demented Parkinsonian Patients. Acta Neurologica Scandinavica, 107, 252-255. http://dx.doi.org/10.1034/j.1600-0404.2003.00081.x

[30] van Laar, T., De Deyn, P.P., Aarsland, D., Barone, P. and Galvin, J.E. (2011) Effects of Cholinesterase Inhibitors in Parkinson's Disease Dementia: A Review of Clinical Data. CNS Neuroscience \& Therapeutics, 17, 428-441. http://dx.doi.org/10.1111/j.1755-5949.2010.00166.x

[31] Wang, C.F., Ma, Y.X., Xie, S.Z., Li, W.B., Zhang, B.L. and Tao, G.S. (1999) The Study of Reinhartdt and Sea Cucumber Capsule on the Efficacy and Mechanism of Action in the Dementia Model. In: Ma, Y.X., Wang, C.F. and Shi, F,Y., Eds., New Progress of Aging and Geriatrics, 1st Edition, FU Dan University Press, Shanghai, 477-487.

[32] Lv, J., Jia, H., Jiang, Y., Ruan, Y., Liu, Z., Yue, W., Beyreuther, K., Tu, P. and Zhang, D. (2009) Tenuifolin, an Extract Derived from Tenuigenin, Inhibits Amyloid-Beta Secretion in Vitro. Acta Physiologica, 196, 419-425. http://dx.doi.org/10.1111/j.1748-1716.2009.01961.x

[33] Jia, H., Jiang, Y., Ruan, Y., Zhang, Y., Ma, X., Zhang, J., Beyreuther, K., Tu, P. and Zhang, D. (2004) Tenuigenin Treatment Decreases Secretion of the Alzheimer's Disease Amyloid Betaprotein in Cultured Cells. Neuroscience Letters, 367, 123-128. http://dx.doi.org/10.1016/j.neulet.2004.05.093

[34] Zhou, Z.L., Liang, L.Z. and Yan, Y.X. (2007) Clinical Study of Reinhartdt and Sea Cucumber Capsule Combined with Donepezil in Treating Alzheimer's Disease. Chinese Journal of Integrated Traditional and Western Medicine, 27, 110-113.

[35] Jahagirdar, V. and McNay, E.C. (2012) Thyroid Hormone’s Role in Regulating Brain Glucose Metabolism and Potentially Modulating Hippocampal Cognitive Processes. Metabolic Brain Disease, 27, 101-111. http://dx.doi.org/10.1007/s11011-012-9291-0

[36] Carreón-Rodríguez, A. and Pérez-Martínez, L. (2012) Clinical Implications of Thyroid Hormones Effects on Nervous System Development. Pediatric Endocrinology Reviews, 9, 644-649.

[37] Bauer, M., Goetz, T., Glenn, T. and Whybrow, P.C. (2008) The Thyroid-Brain Interaction in Thyroid Disorders and 
Mood Disorders. Journal of Neuroendocrinology, 20, 1101-1114. http://dx.doi.org/10.1111/j.1365-2826.2008.01774.x

[38] Bunevicius, R. (2009) Thyroid Disorders in Mental Patients. Current Opinion in Psychiatry, 22, 391-395. http://dx.doi.org/10.1097/YCO.0b013e328329e1ae

[39] Schaefer, S., Vogt, T., Nowak, T. and Kann, P.H., German KIMS board (2008) Pituitary Function and the Somatotmphie System in Patients with Idiopathic Parkinson's Disease under Chronic Dopaminersic Therapy. Journal of Neuroendocrinology, 20, 104-109. http://dx.doi.org/10.1111/j.1365-2826.2007.01622.X

[40] Bonuccelli, U., D’Avino, C., Caraccio, N., Del Guerra, P., Casolaro, A., Pavese, N., Del Dotto, P. and Monzani, F. (1999) Thyroid Function and Autoimmunity in Parkinson's Disease: A Study of 101 Patients. Parkinsonism \& Related Disorders, 5, 49-53. http://dx.doi.org/10.1016/S1353-8020(99)00010-3

[41] Oertel, W., Poewe, W., Wolters, E., De Deyn, P.P., Emre, M., Kirsch, C., Hsu, C., Tekin, S. and Lane, R. (2008) Effects of Rivastigmine on Tremor and Other Motor Symptoms in Patients with Parkinson's Disease Dementia: A Retrospective Analysis of a Double-Blind Trial and an Open-Label Extension. Drug Safety, 31, 79-94.

http://dx.doi.org/10.2165/00002018-200831010-00007 